\title{
Glandular Dose of Full Field Digital Mammography in Korean Women Based on Specific Factors
}

\author{
Seung Hee $\operatorname{Han}^{1}$, Bong Joo Kang ${ }^{1,}{ }^{*}$, Ji Eun Baek ${ }^{1}$, Hyun Sil Lee ${ }^{1}$ and Sung Hun Kim ${ }^{1}$ \\ ${ }^{1}$ Department of Radiology, Mary's Hospital, College of Medicine, the Catholic University of Korea, Seoul, South Korea \\ "Corresponding author: Bong Joo Kang, Department of Radiology, Mary's Hospital, College of Medicine, the Catholic University of Korea, 222, Banpo-daero, Seocho-gu, Seoul, \\ 06591, South Korea. Tel: +82-222586253, Fax: +82-25996771, Email: lionmain@catholic.ac.kr \\ Received 2017 October 17; Revised 2018 June 27; Accepted 2018 July 10.
}

\begin{abstract}
Background: Mammographic screening for breast cancer has been proved to reduce mortality. However, because of the potential harm of ionizing radiation, radiation dose management has been issued.

objectives: We investigated the influence of several factors on the radiation dose change in full-field digital mammography(FFDM) using a radiation dose management system in Korean women.

Patients and Methods: Using an existing radiation dose management system (Radimetrics ${ }^{\mathrm{TM}}$ ), radiation dose tracking, monitoring, and statistical analyses were conducted. Information including parameters, utilization data, and a dose report were sent to the conventional picture archiving, communication system, and radiation dose management system. We reviewed the data and compared the parameters (exposure, glandular dose, compression thickness, and compression force) between two different devices, among classifications (plain, spot and magnification view, and implant), and between control modes (auto and manual). An association between compression thickness and glandular dose was evaluated. Finally, the glandular dose differences based on age, device, classification, control mode, exposure, compression thickness, and compression force were additionally investigated.

Results: From February 25th to June 30th, 2015, a total of 15665 mammogram images of 3958 patients were performed and sent to the conventional picture archiving and communication system (PACS) and the radiation dose management system. A significant difference was observed in glandular dose, compression thickness, compression force, and exposure depending on the type of device $(P<0.05)$. There were significant differences in all of the parameters among the plain view, spot and magnification view, and implant image $(\mathrm{P}<0.05)$. There was a significant difference in compression thickness and compression force depending on the control mode. A strong association was observed between the compression thickness and glandular dose $(\mathrm{P}<0.05)$.

Conclusion: There was glandular dose difference according to specific factors including device type, classification, and control mode. Radiation dose management system is useful for identifying factors that affect radiation dose.
\end{abstract}

Keywords: Radiation Dosage, Digital Mammography, Breast

\section{Background}

Mammographic screening is proved to reduce mortality from breast cancer (1). Use of ionizing radiation is considered a potential harm due to the possible risk of inducing cancer in patients $(1,2)$. It is generally agreed that radiation dose per examination is a crucial parameter for evaluation of the radiation-induced breast cancer risk from mammographic screening (1-4). Recently, general consensus about the importance of radiation dose management for patient safety has been established, and dose reduction has become an important issue in patient safety (5-7). Women often receive screening mammograms throughout their lifetime; however, concern is increasing regarding radiation dosage and radiation-induced breast cancer $(8,9)$.
Several radiation dose management software programs are now used in clinical practice to recruit and analyze patient radiation dose data (10). Radiation dose management systems could help radiologists optimize protocols, reduce radiation dose, and manage quality. To our knowledge, there are no previous data on the application of this radiation dose management system in mammography.

\section{Objectives}

In our study, we investigated the factors associated with an increased radiation dose in full-field digital mammography (FFDM) and the clinical usefulness of the radiation dose management system in FFDM. 


\section{Patients and Methods}

\subsection{Patients}

Our institutional review board approved this prospective study and waived informed patient consent. We performed radiation dose tracking, monitoring, and statistical analysis using an existing radiation dose management system (Radimetrics ${ }^{\mathrm{TM}}$ [Bayer HealthCare, Whippany, NJ]) from February 25th to June 30th, 2015. During this period, a total of 15665 images were obtained from 3958 patients who underwent a mammogram for screening or diagnosis. The mean age of the patients was 52.94 years (range, 22 -58). We used two different devices: Lorad Selenia (Hologic Company, Bedford, MA, USA) and Mammomat Inspiration (Siemens, Erlangen, Germany). The Mammomat Inspiration unit was used from January 1, 2009, and the Lorad Selenia was used from August 1, 2006. Utilization data, parameters, and mammography dosage reports were sent to the conventional picture archiving and communication system(PACS) and the Radimetrics ${ }^{\mathrm{TM}}$ Enterprise platform. The radiation dose management system extracted the mean glandular dose from the digital imaging and communications in medicine (DICOM) tag 'Organ Dose (0040, 0316)', as defined in the DICOM Standard, and presented it to the application for data aggregation for analysis (11). The radiation dose management system showed the mean glandular dose per laterality (left or right) of the breast according to the ' $\mathrm{L}$ ' or ' $\mathrm{R}$ ' value in the image level DICOM tag 'Laterality (0020, 0062)' and summed the mean glandular dose within the same laterality (11). Data regarding exposure, compression thickness, and compression force were also extracted from the DICOM tags of each image and used for analysis. We reviewed the data using our personal computers by accessing the web server of the radiation dose management system. Patient and image (view) characteristics are shown in Table 1.

\subsection{Analyzing Factors Affecting Radiation Dose}

We compared how the parameters (glandular dose, exposure, compression thickness, and compression force) are influenced by the devices, classifications, and control modes. We evaluated the association between compression thickness and glandular dose.

Additionally, we investigated the difference in glandular dose depending on age, device, classification (plain, spot and magnification view, implant), control mode (auto, manual), exposure ( $\mu \mathrm{As}$, microampere), compression thickness, and compression force.

\subsection{Statistical Analysis}

All statistical analyses were performed using the SAS Enterprise software package Guide 5.1 (SAS Institute, Inc., Cary, North Carolina, USA) or R software version 2.15.3

\begin{tabular}{|c|c|}
\hline Characteristics & Values \\
\hline \multicolumn{2}{|c|}{ Patient $(n=3958)$} \\
\hline \multicolumn{2}{|l|}{ Age } \\
\hline Mean (SD) & $52.94(10.17)$ \\
\hline Median (min - max) & $53(22-85)$ \\
\hline \multicolumn{2}{|l|}{ Device No. (\%) } \\
\hline Lorad selenia & $2405(60.76)$ \\
\hline Mammomat inspiration & $1553(39.24)$ \\
\hline \multicolumn{2}{|l|}{ Image number per patient } \\
\hline Mean (SD) & $3.74(0.84)$ \\
\hline Median (min - max) & $4(1-9)$ \\
\hline \multicolumn{2}{|l|}{ Sum of glandular dose (mGy) } \\
\hline Mean (SD) & $7.09(3.49)$ \\
\hline Median (min - max) & $6.66(0.74-46.93)$ \\
\hline IQR & $4.44-8.85$ \\
\hline \multicolumn{2}{|c|}{ Image $($ view $)(n=15665)$} \\
\hline \multicolumn{2}{|l|}{ Device No. (\%) } \\
\hline Lorad selenia & $9086(58)$ \\
\hline Mammomat inspiration & $6579(42)$ \\
\hline \multicolumn{2}{|l|}{ Classification No. (\%) } \\
\hline Plain & $14925(95.28)$ \\
\hline Spot and magnification & $570(3.64)$ \\
\hline Implant & $170(1.09)$ \\
\hline \multicolumn{2}{|l|}{ Control mode No. (\%) } \\
\hline Auto & $15416(98.41)$ \\
\hline Manual & $249(1.59)$ \\
\hline \multicolumn{2}{|l|}{ Exposure $(\mu \mathbf{A s})$} \\
\hline Mean $(S D)$ & $94510.49(31969.93)$ \\
\hline Median (Q1 - Q3) & $89590(74210-110000)$ \\
\hline \multicolumn{2}{|l|}{ Compression thickness (mm) } \\
\hline Mean (SD) & $47(12.70)$ \\
\hline Median (Q1 - Q3) & $47(39-55)$ \\
\hline \multicolumn{2}{|l|}{ Compression force $(\mathrm{N})$} \\
\hline Mean (SD) & $101.33(28.66)$ \\
\hline Median (Q1 - Q3) & $100.70(84.20-117.80)$ \\
\hline \multicolumn{2}{|l|}{ Glandular dose (mGy) } \\
\hline Mean (SD) & $1.79(0.74)$ \\
\hline Median (Q1 - Q3) & $1.72(1.21-2.21)$ \\
\hline
\end{tabular}

Abbreviations: IQR, interquartile range (means standard deviation); $\mu \mathrm{As}$, microampere; N, Newton; Q1, lower quartile, Q3, upper quartile; SD, standard deviation.

(R Foundation for Statistical Computing, Vienna, Austria; https://www.r-project.org/). We performed normality assessment of data before choosing the statistic tests. The normality was assessed by performing the KolmogorovSmirnov test on the parameters (glandular dose, exposure, compression thickness, and compression force). The $\mathrm{P}$ value $<0.01$ and the number of subjects in each comparative group was at least 200, we used parametric analysis, ttest and ANOVA. comparisons of the parameters (glandular dose, exposure, compression thickness, and compression 
force) between devices and between the control modes were conducted using independent Student's t-tests. Comparison of the parameters among classifications and the association between compression thickness and glandular dose were completed using an ANOVA with Tukey-Kramer post-hoc adjustment. Univariate and multivariate logistic regressions for glandular dose 75 th percentile (predict: $\geq$ glandular dose 75 th percentile) were used to investigate the difference in glandular dose depending on age, device, classification, control mode, exposure, compression thickness, and compression force.

\section{Results}

\subsection{Patients}

The mean age of this study group was 52.94 years; the range was from 22 - 85 years (Table 1 ). The mean number of views per patient was 3.74 (range, 1 - 10 views). The sum of glandular dose per patient varied from 0.74 to $46.93 \mathrm{mGy}$. The mean glandular dose per patient and per view were $7.09 \mathrm{mGy}$ and $1.79 \mathrm{mGy}$, respectively.

\subsection{Characteristics According to Device, Classification, and Control Mode}

A significant glandular dose difference between the two devices was observed (Table 2 and Figure 1A). Glandular dose, compression thickness, and compression force were significantly lower in Mammomat Inspiration $(\mathrm{P}<0.05)$. Exposure was also significantly lower in Mammomat Inspiration $(\mathrm{P}<0.05)$.

There were significant differences in all parameters between classifications (plain view, spot and magnification view, and implant image) $(\mathrm{P}<0.05)$ (Table 3$)$. In the spot and magnification view, the mean glandular dose was significantly higher than in the plain and implant classifications (2.27 mGy $>1.77 \mathrm{mGy}$ and $1.68 \mathrm{mGy}$, respectively) (Figure $1 \mathrm{~B})$.

Compression thickness was significantly thinner in auto control mode $(\mathrm{P}<0.05)$, and compression force was significantly higher in auto control mode $(\mathrm{P}<0.05)$. We found no significant difference between the two control modes in glandular dose $(\mathrm{P}=0.2913)$ or exposure $(\mathrm{P}=$ 0.1519) (Table 4 and Figure $1 C$ ).

\subsection{Association Between Compression Thickness and Glandu- lar Dose}

There was a strong association between the compression thickness and glandular dose in both device types ( $P$ $<0.05$ ) (Table 5 and Figure 2).

\subsection{Factors Affecting Glandular Dose}

A negative correlation was observed between patient age and glandular dose. There was a difference in glandular dose according to device type. Glandular dose was higher in the spot and magnification view than in the routine plain mammography and implant view. There were positive correlations between glandular dose and exposure, compression thickness, and compression force (Table 6).

\section{Discussion}

Recently, the relationship between radiation exposure and cancer risk has been frequently discussed (4,12-14). In a cohort study of solid cancer incidence in atomic bomb survivors, the excess risks of all solid cancers exhibited significant variation based on gender, exposed age, and attained age. For example, in a patient who had been exposed to an atomic bomb at age 30, the rate of solid cancer in this patient would have significantly increased by age 70 (approximately 35\% per Gy for men and 58\% per Gy for women). Despite attained age, this experience of radiation exposure persistently increases the cancer rate throughout an individual's life. Another study reported that there was a significantly increased risk of breast cancer associated with radiation exposure (13).

Two groups have estimated cancer risk based on the data from Hiroshima and Nagasaki atomic bomb survivors traced over more than 50 years and from data of other cohort studies (12-14): The United States national academy of sciences biologic effects of ionizing radiation (BEIR) VII group and the international commission on radiological protection (ICRP) $(5,15)$. A linear, no-threshold doseresponse relationship was used in these studies to evaluate how the radiation dose is associated with the risk of radiation-induced solid cancers, including breast cancer. The BEIR VII group included the age dependency in a previous risk estimation about radiation-induced cancer incidence and mortality (15). The mean glandular dose is defined as the dose delivered to the glandular breast tissue and is considered to be a reasonable quantity for comparing relative risk for mammography (16). Hendrick et al. reported that the average mean glandular radiation doses of two-view digital mammography and screenfilm mammography were 3.7 and 4.7 mGy, respectively (3). When these mean glandular radiation doses are adjusted by the international commission on radiological protection (ICRP) tissue-weighting factor ( 0.12 for breast tissue), an average effective dose of $0.56 \mathrm{mSv}$ and $0.44 \mathrm{mSv}$ are obtained (5). According to BEIR VII data, annual screening digital or screen-film mammography performed in women aged 40 - 80 years is associated with a lifetime attributable risk (LAR) of fatal breast cancer of 20 - 25 cases per 100000 women. 


\begin{tabular}{|c|c|c|c|}
\hline & Lorad selenia $(\mathbf{n}=\mathbf{9 0 8 6})$ & Mammomat inspiration $(n=6579)$ & Pvalue $^{\mathrm{a}}$ \\
\hline Glandular dose (mGy) & & & $<0.0001$ \\
\hline Mean (SD) & $2.16(0.69)$ & $1.28(0.46)$ & \\
\hline Median (Q1 - Q3) & $2.06(1.72-2.47)$ & $1.17(0.96-1.48)$ & \\
\hline Exposure $(\mu \mathrm{As})$ & & & 0.0002 \\
\hline Mean (SD) & $95347.53(28271.42)$ & $93354.47(36436.87)$ & \\
\hline Median (Q1 - Q3) & $91200(77100-110400)$ & $86930(69960-109810)$ & \\
\hline Compression thickness (mm) & & & $<0.0001$ \\
\hline Mean (SD) & $47.99(12.19)$ & $45.63(13.26)$ & \\
\hline Median (Q1 - Q3) & $49(40-56)$ & $46(38-53)$ & \\
\hline Compression force $(\mathrm{N})$ & & & $<0.0001$ \\
\hline Mean (SD) & $102.37(31.26)$ & $99.90(24.56)$ & \\
\hline Median (Q1 - Q3) & $102.30(80.09-120.10)$ & $99.70(84.60-113.80)$ & \\
\hline
\end{tabular}

Abbreviations: $\mu$ As, microampere; N, Newton; SD, standard deviation, $\mathrm{Q} 1$ = lower quartile, $\mathrm{Q} 3=$ upper quartile.

${ }^{\mathrm{a}} \mathrm{P}$ values were calculated using the independent student's t-test.

A

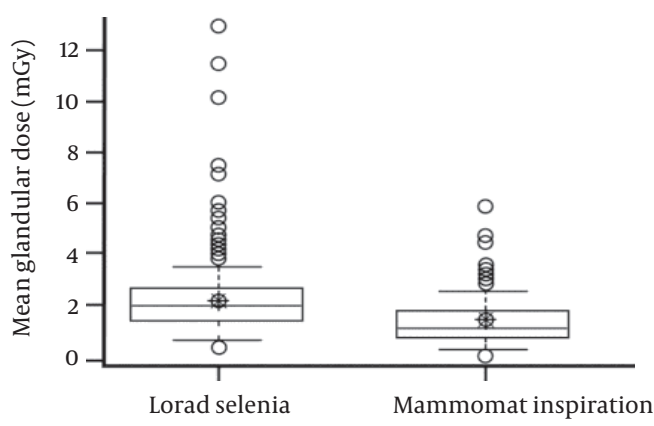

B

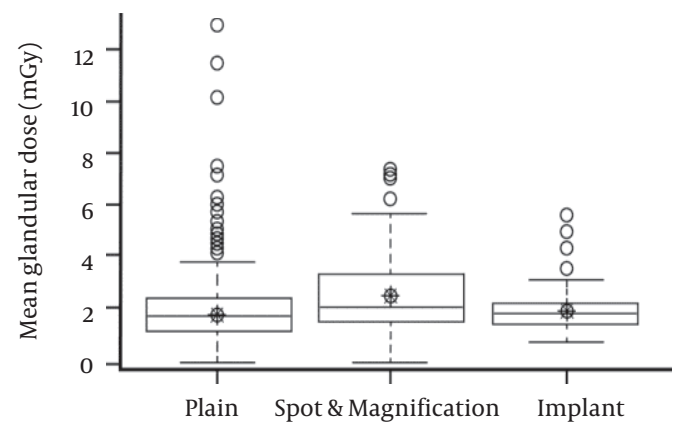

○

O

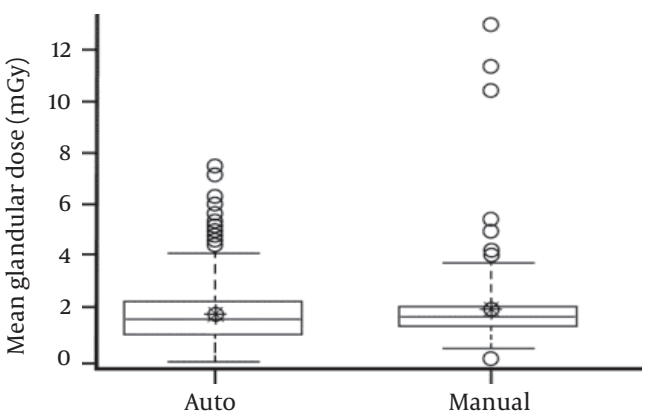

Figure 1. Box-and-whisker plots show glandular dose comparison by parameters. A, There was a significant difference in dose according to device $(\mathrm{P}<0.05)$. B, There was a significant difference in dose according to classification $(\mathrm{P}<0.05)$. $\mathrm{C}$, There was no significant difference according to control mode $(\mathrm{P}=0.29)$.

The risk of radiation-induced breast cancers due to mammographic screening is minimal $(2,3,17)$. It is generally agreed that radiation dose per examination is crucial parameter (1-4). Because mammography has been used for periodic screening of women, there is notable concern regarding the radiation dose received from mammography and the risk of radiation-induced breast cancer. This is significant because women should undergo screening mammography dozens of times throughout their lives. So, radiation dose per examination should be properly and systemically managed.

There are several radiation dose management software 


\begin{tabular}{|c|c|c|c|c|c|c|c|}
\hline & \multirow[t]{2}{*}{ Plain $(n=14925)$} & \multirow[t]{2}{*}{ Spot and mag $(n=570)$} & \multirow[t]{2}{*}{ Implant $(\mathbf{n}=\mathbf{1 7 0})$} & \multirow[t]{2}{*}{ Pvalue } & \multicolumn{3}{|c|}{ P value (Tukey-Kramer post-hoc test) } \\
\hline & & & & & $\begin{array}{c}\text { Plain } \\
\text { versus spot } \\
\text { and mag }\end{array}$ & $\begin{array}{c}\text { Plain } \\
\text { versus } \\
\text { implant }\end{array}$ & $\begin{array}{l}\text { Spot and } \\
\text { Mag versus } \\
\text { implant }\end{array}$ \\
\hline Glandular dose (mGy) & & & & $<0.0001$ & $<0.0001$ & 0.2568 & $<0.0001$ \\
\hline Mean (SD) & $1.77(0.72)$ & $2.27(1.11)$ & $1.68(0.63)$ & & & & \\
\hline Median (Q1 - Q3) & $1.71(1.20-2.20)$ & $1.94(1.42-2.97)$ & $1.63(1.29-1.90)$ & & & & \\
\hline Exposure $(\mu \mathrm{As})$ & & & & $<0.0001$ & $<0.0001$ & $<0.0001$ & $<0.0001$ \\
\hline Mean (SD) & $96023.52(31458.18)$ & $57736.37(23222.09)$ & $\begin{array}{l}84976.59 \\
(25911.89)\end{array}$ & & & & \\
\hline Median (Q1 - Q3) & $\begin{array}{c}90880(75400- \\
111200)\end{array}$ & $54130(43120-68000)$ & $\begin{array}{c}84350(74500- \\
90020)\end{array}$ & & & & \\
\hline $\begin{array}{l}\text { Compression } \\
\text { thickness }(\mathbf{m m})\end{array}$ & & & & $<0.0001$ & $<0.0001$ & $<0.0001$ & $<0.0001$ \\
\hline Mean (SD) & $47.13(12.03)$ & $39.69(21.10)$ & $59.89(18.17)$ & & & & \\
\hline Median (Q1 - Q3) & $48(39-55)$ & $39(29-47)$ & $63(48-72)$ & & & & \\
\hline Compression force $(\mathrm{N})$ & & & & $<0.0001$ & $<0.0001$ & $<0.0001$ & $<0.0001$ \\
\hline Mean (SD) & $102.15(28.22)$ & $93.63(27.42)$ & $55.41(30.21)$ & & & & \\
\hline Median (Q1 - Q3) & $\begin{array}{c}101.70(84.55- \\
119.10)\end{array}$ & $98.10(77.30-111.20)$ & $58.07(47.10-71.19)$ & & & & \\
\hline
\end{tabular}

Abbreviations: $\mu$ As, microampere; $\mathrm{N}$, Newton; $\mathrm{SD}$, standard deviation, $\mathrm{Q} 1$ = lower quartile, $\mathrm{Q} 3=$ upper quartile.

${ }^{a} \mathrm{P}$ values were calculated using the ANOVA with Tukey-Kramer post-hoc test.

\begin{tabular}{|c|c|c|c|}
\hline & $\operatorname{Auto}(n=15416)$ & $\operatorname{Manual}(\mathbf{n}=\mathbf{2 4 9})$ & Pvalue $^{a}$ \\
\hline Glandular dose (mGy) & & & 0.2913 \\
\hline Mean (SD) & $1.79(0.72)$ & $1.88(1.40)$ & \\
\hline Median (Q1 - Q3) & $1.72(1.21-2.22)$ & $1.64(1.27-2)$ & \\
\hline Exposure $(\mu \mathrm{As})$ & & & 0.1519 \\
\hline Mean (SD) & $94584.03(31575.30)$ & $89957.55(50633.83)$ & \\
\hline Median (Q1 - Q3) & $90300(74370-110400)$ & $80020(71020-90020)$ & \\
\hline Compression thickness (mm) & & & $<0.0001$ \\
\hline Mean (SD) & $46.76(12.34)$ & $61.37(22.73)$ & \\
\hline Median (Q1 - Q3) & $47(39-55)$ & $66(56-75)$ & \\
\hline Compression force $(\mathrm{N})$ & & & $<0.0001$ \\
\hline Mean (SD) & $102.05(27.98)$ & $56.67(34.72)$ & \\
\hline Median (Q1 - Q3) & $101.60(84.55-118.50)$ & $57.84(46$ - 71.19$)$ & \\
\hline
\end{tabular}

Abbreviations: $\mu$ As, microampere; N, Newton; SD, standard deviation, $\mathrm{Q} 1=$ lower quartile, $\mathrm{Q} 3=$ upper quartile.

${ }^{\mathrm{a}} \mathrm{P}$ values were calculated using the independent student's t-test.

packages that can recruit and analyze patient radiation dose data. By taking advantage of these radiation dose management systems, radiologists can optimize protocols, reduce radiation doses, and manage quality. There are rare previous data on the application of radiation dose management systems in mammography. In this study, we investigated the clinical usefulness of radiation dose management systems in full-field digital mammography (FFDM), and we also evaluated the factors associated with increased radiation doses in FFDM using Radimetrics ${ }^{\mathrm{TM}}$.

The linear positive relationship between compression thickness and glandular dose was well known in the prior studies (18-21). The correlations between exposure and glandular dose in our study can be explained by the linear increase in dose with exposure, which is related to beam quantity (22). There were strong relationships between glandular radiation dose and various parameters, such as age, device, classification (plain, spot and magnification view, implant), exposure, compression thickness, and compression force $(\mathrm{P}<0.05)$. These results suggest that radiologists can monitor and control a patient's glandular dose by modifying device type, image classification, exposure, compression thickness and compression force under the guidance of a radiation dose management system. This effort can reduce the patient's radiation exposure doses.

A significant glandular dose difference was noted be- 


\begin{tabular}{|c|c|c|c|c|}
\hline \multirow[t]{2}{*}{ Compression thickness } & \multicolumn{2}{|c|}{ Lorad selenia $(\mathbf{n}=\mathbf{9 0 8 6})$} & \multicolumn{2}{|c|}{ Mammomat inspiration $(n=6579)$} \\
\hline & $\mathbf{n}$ & Glandular dose (mGy) & $\mathbf{n}$ & Glandular dose (mGy) \\
\hline Thickness $<2 \mathrm{~cm}$ & 141 & $1.72(1.74)$ & 144 & $1.62(0.46)$ \\
\hline $2 \leq$ Thickness $\leq \mathbf{3} \mathrm{cm}$ & 549 & $1.56(0.63)$ & 631 & $1.76(0.64)$ \\
\hline $\mathbf{3}<$ Thickness $\leq \mathbf{4} \mathrm{cm}$ & 1603 & $2(0.63)$ & 1415 & $1.01(0.24)$ \\
\hline $4<$ Thickness $\leq 5 \mathrm{~cm}$ & 2814 & $2.22(0.63)$ & 2135 & $1.16(0.31)$ \\
\hline $5<$ Thickness $\leq 6 \mathrm{~cm}$ & 2770 & $2.30(0.62)$ & 1548 & $1.34(0.38)$ \\
\hline $6<$ Thickness $\leq 7 \mathrm{~cm}$ & 975 & $2.18(0.55)$ & 562 & $1.54(0.49)$ \\
\hline $7<$ Thickness $\leq \mathbf{8 c m}$ & 200 & $2.33(0.82)$ & 117 & $1.78(0.63)$ \\
\hline Thickness $>8 \mathrm{~cm}$ & 34 & $2.28(1.28)$ & 27 & $1.47(1.20)$ \\
\hline Pvalue $^{a}$ & \multicolumn{2}{|c|}{$<0.0001^{\mathrm{b}}$} & \multicolumn{2}{|c|}{$<0.0001^{\mathrm{c}}$} \\
\hline
\end{tabular}

${ }^{\mathrm{a}} \mathrm{P}$ values were calculated using the ANOVA with Tukey-Kramer post-hoc test.

${ }^{\mathrm{b}}$ Tukey-Kramer post-hoc test: In post-hoc test, contrasts between groups [1st vs. 2nd], [3rd vs. 8th], [4th vs. 6th], [4th vs. 7th], [4th vs. 8th], [5th vs. 7th], [5th vs. 8th], [6th vs. 7th], [6th vs. 8th] and [7th vs. 8th] were statistically non-significant. All other contrasts were statistically significant [All P values $<0.001]$.

${ }^{\mathrm{c}}$ Tukey-Kramer post-hoc test: In post-hoc test, contrasts between groups [1st vs. 6th], [1st vs. 8th], [2nd vs. 7th], [5th vs. 8th] and [6th vs. 8th] were non-significant. All other contrasts were statistically significant [All P Values $<0.03$ ].

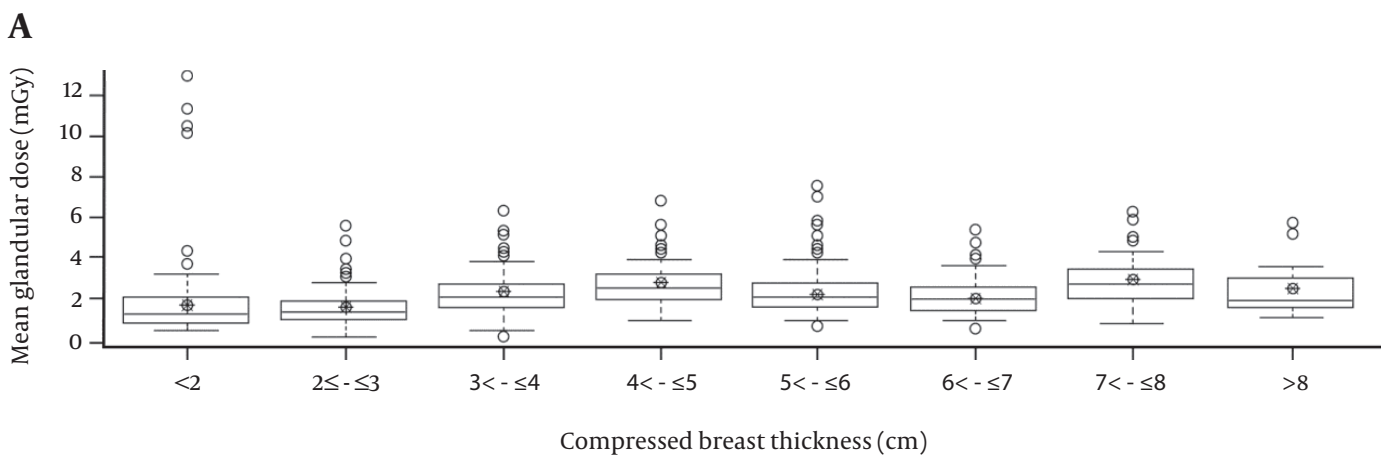

B

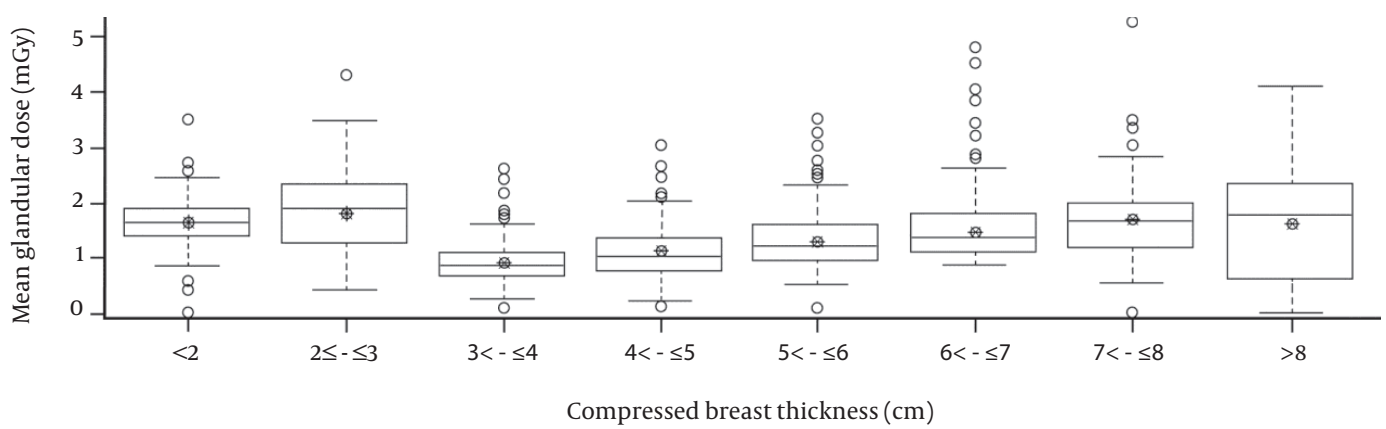

Figure 2. Box-and-whisker plots show the association between compression thickness and glandular dose. A and B, There was a strong association between the compression thickness and glandular dose in both device types $(\mathrm{P}<0.05)$ (A: Lorad Selenia [ $\mathrm{n}=8096]$, B: Mammomat Inspiration [ $\mathrm{n}=6579])$.

tween the two devices (Lorad Selenia, Mammomat Inspiration). Two units have different age. The Mammomat Inspiration unit was used from January 1, 2009, and the Lorad Selenia was used from August 1, 2006. The difference between two vendors as well as the difference in the age of devices was suggested to have contributed to the glandular dose difference. Differences in compression thickness, compression force, and exposure were observed in two devices. These findings indicate that monitoring device performance with a radiation dose management system can be used for FFDM quality control.

There were significant differences among mammogram classification (plain view, spot and magnification view, and implant view), glandular dose, exposure, com- 


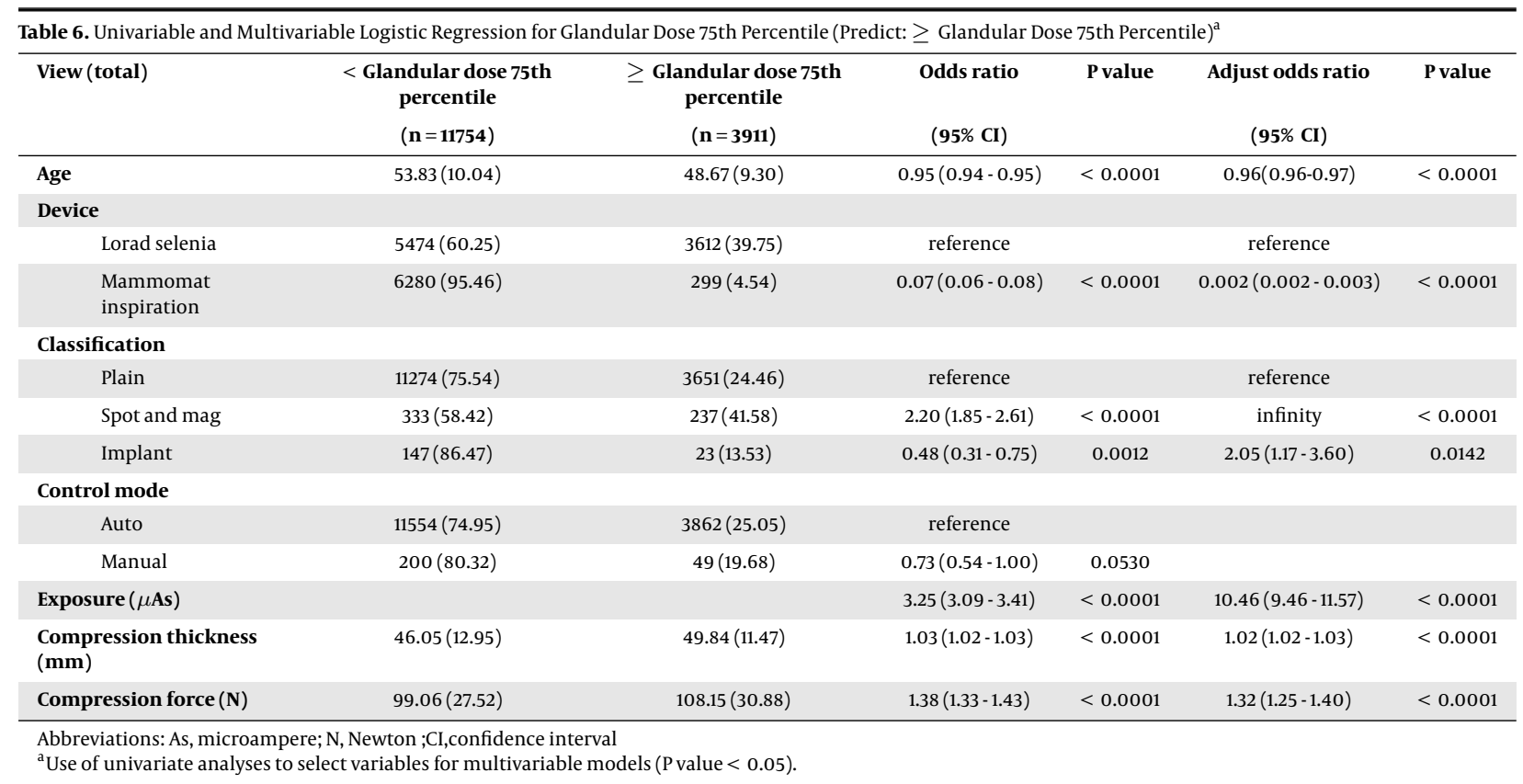

pression thickness and compression force $(\mathrm{P}<0.05)$. The spot and magnification view showed a higher glandular radiation dose than the plain and implant view (mean \pm $\mathrm{SD}, 2.27 \pm 1.11 \mathrm{mGy})(\mathrm{P}<0.05)$. The spot and magnification views were performed with routine FFDM (more than four views); therefore, the patient's radiation dose exposure would be much higher. In this study, the patient who was exposed to the highest radiation dose (46.93 mGy) was a 41-year-old woman who underwent four FFDM and six spot and magnification views with Lorad Selenia. Using a management system, when a spot and magnification view is needed, can help monitor a patient's exposure dose and more precisely control the overall radiation exposure.

In comparison with the control mode, compression thickness and compression force showed a significant difference in the two groups. In the implant view, there was a difference in compression technique. Generally, in implant view, the breasts are weakly compressed in manual mode; otherwise, implants might be in danger of rupture or it might be difficult to obtain an adequate implant view. Although there was no significant difference between the two control modes in glandular dose $(\mathrm{P}=0.2913)$ or exposure $(\mathrm{P}=0.1519)$, the total radiation dose per patient could be much higher than other types of images because the implant views consist of a total of eight images (four displacement views and four non-displacement views).

There was a strong association between the compression thickness and glandular dose $(\mathrm{P}<0.05)$. With a thinner compression thickness, a lower glandular radiation dose was noted in both device types. This finding indicates that in mammograms, it is not sufficient to emphasize the importance of the technologist's experience with the mammogram technique involving compressing the breast enough to lower the radiation dose.

In this study, several factors were correlated with glandular dose, including patient age, device type, classification, exposure, compression thickness, and compression force. A negative correlation was observed between patient age and glandular dose. There was a difference in glandular dose according to device type. Glandular dose was higher in the spot and magnification view than in routine plain mammography and implant views. There were positive correlations between glandular dose and exposure and between compression thickness and compression force.

Our study had several limitations. First, images included in this study were acquired over the course of approximately four months. However, the number of images were sufficient for statistical analyses. Second, this study included mammographic images from one institution including only two devices; the institution is a tertiary medical center. This fact may cause a selection bias of patients and devices. Third, given the sample size imbalance between two devices, judgement may be biased. At last, Radimetrics $^{\mathrm{TM}}$ is not a real dosimeter and estimate doses are based on the specific conditions of the mammography that are planned to be accomplished. The reason for performing this study on real patients is that we can simulate some different patient groups based on the difference in relevant and important factors affecting the mammography radiation and then calculate the dose of each virtual patient. 
In a center with good quality control and wellmanaged devices, such as our center, the radiation dose for one mammography view is not high. Quality control and device management are very important in patient care, and centers and hospitals that use mammography should always endeavor to minimize the radiation dose as much as possible.

In young women, cancer risk resulting from radiation exposure is much higher than in older women; a guideline considering age and adequate breast compression is needed in mammography examination. The radiation exposure dose is significantly higher in patients who have undergone implant views or spot and compression views. Serious concern regarding per patient radiation dose should be exercised with these patients, and repeat study should be avoided as much as possible.

In conclusion, using a radiation dose management system, we could easily collect data and parameters of patients who underwent mammography during a specific period to analyze the factors affecting radiation dose. There was glandular dose difference according to specific factors including device type, classification, and control mode.

\section{Footnotes}

Authors' Contributions: None declared.

Financial Disclosure: None declared.

Funding/Support: The statistical consultation was supported by a grant of the Korean Health Technology R \& D project, Ministry of Health and Welfare, Republic of Korea (HI14C1731).

\section{References}

1. Independent U. K. Panel on Breast Cancer Screening. The benefits and harms of breast cancer screening: an independent review. Lancet. 2012;380(9855):1778-86. doi: 10.1016/S0140-6736(12)61611-0. [PubMed: 23117178].

2. Yaffe MJ, Mainprize JG. Risk of radiation-induced breast cancer from mammographic screening. Radiology. 2011;258(1):98-105. doi: 10.1148/radiol.10100655. [PubMed: 21081671].

3. Hendrick RE. Radiation doses and cancer risks from breast imaging studies. Radiology. 2010;257(1):246-53. doi: 10.1148/radiol.10100570. [PubMed: 20736332].

4. O'Connor MK, Li H, Rhodes DJ, Hruska CB, Clancy CB, Vetter RJ. Comparison of radiation exposure and associated radiation-induced cancer risks from mammography and molecular imaging of the breast. Med Phys. 2010;37(12):6187-98. doi: 10.1118/1.3512759. [PubMed: 21302775]. [PubMed Central: PMC2997811]

5. The 2007 Recommendations of the International Commission on Radiological Protection. ICRP publication 103. Ann ICRP. 2007;37(2-4):1332. doi: 10.1016/j.icrp.2007.10.003. [PubMed: 18082557].
6. Butt WP, Walkowiak J. The Ionising Radiation (Medical Exposure) regulations (IRME) 2000-radiological considerations. J Bone Joint Surg Br. 2002;84(6):781-2. [PubMed: 12211664].

7. Kase KR. Radiation protection principles of NCRP. Health Phys 2004;87(3):251-7. [PubMed: 15303061]

8. Brenner DJ, Elliston CD, Hall EJ, Berdon WE. Estimates of the cancer risks from pediatric CT radiation are not merely theoretical: comment on "point/counterpoint: in x-ray computed tomography, technique factors should be selected appropriate to patient size. against the proposition". Med Phys. 2001;28(11):2387-8. doi: 10.1118/1.1415074. [PubMed: 11764047].

9. Linton OW, Mettler FA Jr, National Council on Radiation P; Measurements. National conference on dose reduction in CT, with an emphasis on pediatric patients. AJR Am J Roentgenol. 2003;181(2):321-9. doi 10.2214/ajr.181.2.1810321. [PubMed: 12876005].

10. Nicol RM, Wayte SC, Bridges AJ, Koller CJ. Experiences of using a commercial dose management system (GE DoseWatch) for CT examinations. Br J Radiol. 2016;89(1057):20150617. doi: 10.1259/bjr.20150617. [PubMed: 26539632].

11. Baek JE, Kang BJ, Kim SH, Lee HS. Radiation dose affected by mammographic composition and breast size: first application of a radiation dose management system for full-field digital mammography in Korean women. World J Surg Oncol. 2017;15(1):38. doi: 10.1186/s12957-017 1107-6. [PubMed: 28153022]. [PubMed Central: PMC5290600].

12. Preston DL, Pierce DA, Shimizu Y, Cullings HM, Fujita S, Funamoto $S$, et al. Effect of recent changes in atomic bomb survivor dosimetry on cancer mortality risk estimates. Radiat Res. 2004;162(4):377-89. [PubMed: 15447045].

13. Preston DL, Ron E, Tokuoka S, Funamoto S, Nishi N, Soda M, et al. Solid cancer incidence in atomic bomb survivors: 1958-1998. Radiat Res. 2007;168(1):1-64. doi:10.1667/RR0763.1. [PubMed: 17722996].

14. Preston DL, Shimizu Y, Pierce DA, Suyama A, Mabuchi K. Studies of mortality of atomic bomb survivors. Report 13: solid cancer and noncancer disease mortality: 1950-1997. 2003. Radiat Res. 2012;178(2):AV146-72. [PubMed: 22870966].

15. National Research Council. Health risks from exposure to low levels of ionizing radiation: BEIR VII phase 2. 7. Washington, D.C: National Academies Press; 2006.

16. Dance DR, Young KC, van Engen RE. Further factors for the estimation of mean glandular dose using the United Kingdom, European and IAEA breast dosimetry protocols. Phys Med Biol. 2009;54(14):4361-72. doi: 10.1088/0031-9155/54/14/002. [PubMed: 19550001].

17. Hauge IH, Pedersen K, Olerud HM, Hole EO, Hofvind S. The risk of radiation-induced breast cancers due to biennial mammographic screening in women aged 50-69 years is minimal. Acta Radiol. 2014;55(10):1174-9. doi: 10.1177/0284185113514051. [PubMed: 24311702].

18. Gentry JR, DeWerd LA. TLD measurements of in vivo mammographic exposures and the calculated mean glandular dose across the United States. Med Phys. 1996;23(6):899-903. doi: 10.1118/1.597824. [PubMed: 8798175].

19. Kruger RL, Schueler BA. A survey of clinical factors and patient dose in mammography. Med Phys. 2001;28(7):1449-54. doi: 10.1118/1.1382606. [PubMed: 11488578].

20. Moran P, Chevalier M, Ten JI, Fernandez Soto JM, Vano E. A survey of patient dose and clinical factors in a full-field digital mammography system. Radiat Prot Dosimetry. 2005;114(1-3):375-9. doi: 10.1093/rpd/nch514. [PubMed:15933140].

21. Bor D, Tukel S, Olgar T, Aydin E. Variations in breast doses for an automatic mammography unit. Diagn Interv Radiol. 2008;14(3):122-6. [PubMed: 18814131].

22. Hatziioannou KA, Psarrakos K, Molyvda-Athanasopoulou E, Kitis G, Papanastassiou E, Sofroniadis I, et al. Dosimetric considerations in mammography. Eur Radiol. 2000;10(7):1193-6. doi: 10.1007/s003309900209. [PubMed: 11003419]. 